Regards sur l'économie allemande

Bulletin économique du CIRAC

$113 \mid 2014$

Varia

\title{
Offensive en trompe-l'œil contre le Pacte européen de stabilité
}

René Lasserre

\section{OpenEdition}

Édition électronique

URL : http://journals.openedition.org/rea/4678

DOI : $10.4000 /$ rea.4678

ISSN : 1965-0787

Éditeur

CIRAC

\section{Édition imprimée}

Date de publication : 15 juillet 2014

Pagination : 1-2

ISSN : 1156-8992

\section{Référence électronique}

René Lasserre, "Offensive en trompe-l'œil contre le Pacte européen de stabilité », Regards sur

l'économie allemande [En ligne], 113 | juillet 2014, mis en ligne le 17 juillet 2014, consulté le 22 septembre 2020. URL : http://journals.openedition.org/rea/4678; DOI : https://doi.org/10.4000/rea. 4678 


\section{Offensive en trompe-l'œil contre le Pacte européen de stabilité}

Outre qu'il avait pour objet principal, et jusqu'alors inédit, de désigner formellement à l'issue des élections au Parlement européen le nouveau président de la Commission européenne en la personne de Jean-Claude Juncker, le dernier sommet européen ne restera pas dans les annales. Si ce n'est qu'il a donné une nouvelle fois l'occasion de relancer le sempiternel débat d'école sur l'assouplissement des règles du Pacte de stabilité, considéré comme la clé d'une nécessaire réorientation de la politique économique européenne.

L'offensive est venue une fois de plus de l'Europe sub-rhénane, à l'initiative de son chef de file naturel, le Président François Hollande, conforté en l'occurrence par l'entrée en scène remarquée du nouveau Président du Conseil italien Matteo Renzi, mais surtout par la " parole révélée " venue d'Allemagne, celle du nouveau Vice-Chancelier socialdémocrate et ministre fédéral de 1'Economie, Sigmar Gabriel. Ce dernier n'a pas hésité, sans doute plus par solidarité partisane que par conviction, et mû par le souci de répondre au désarroi eurosceptique de couches importantes de la population européenne touchées par la crise, à plaider pour un assouplissement des disciplines budgétaires européennes. En cela, il a manifestement cédé un peu vite à la facilité, voire à l'imprudence tribunicienne, puisqu'il ne s'est pas contenté de préconiser l'étalement dans le temps des échéances fixées, allant jusqu'à proposer de réviser le mode de calcul des déficits en déduisant de ceux-ci une partie des efforts consentis par les pays pour procéder aux réformes. La première proposition apparaît, à l'examen, sans réel fondement puisque l'étalement des échéances de retour à l'équilibre a toujours été accordé et appliqué avec la plus large tolérance. Au point que certains pays, au premier rang desquels la France, se sont ingéniés, en toute impunité, à ne pas les respecter. Cette option délibérée de facilité apparaît, à l'expérience, irresponsable car on constate qu'en réalité, elle ne fait que repousser l'assainissement budgétaire et aggraver la situation en accroissant dangereusement la dette des pays en difficulté. Quant à la seconde proposition de modification des bases de calcul audelà des éléments déjà minutieusement pris en compte dans la notion de déficit structurel, elle est plus pernicieuse encore, car elle serait non seulement inapplicable mais conduirait purement et simplement à vider le pacte de toute signification.

Il n'est dès lors pas étonnant que les propositions de Sigmar Gabriel, avancées en amont de la tenue du sommet, aient assez vite fait long feu. Elles furent d'abord fraîchement accueillies par ses partenaires gouvernementaux, au premier rang desquels la Chancelière et son ministre des Finances Wolfgang Schäuble, ce qui conduisit logiquement Sigmar Gabriel à faire marche arrière sur la nécessité d'un réaménagement du Pacte de stabilité et à préconiser une utilisation plus optimale des flexibilités existantes. L'option d'un réaménagement du Pacte fut également

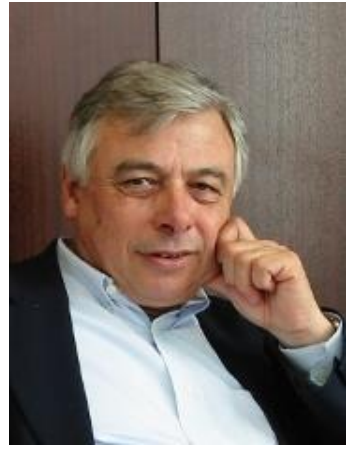

Prof. René Lasserre, Directeur du CIRAC 
ouvertement rejetée par les instances européennes, ainsi que par les banquiers centraux, que ce soit au sein de la Bundesbank ou de la $\mathrm{BCE}$, où des voix autorisées et concordantes, y compris françaises, ont mis explicitement en garde contre tout relâchement pouvant conduire à répéter l'erreur fatale de 2003 et replonger l'Euro dans la crise. Au final, et au-delà de la caution initiale que lui apporta Sigmar Gabriel, le bilan de l'offensive Hollande-Renzi sur la révision du Pacte de stabilité est assez maigre. Elle s'est finalement soldée lors du Sommet de Bruxelles par un ralliement sans surprise et sans panache, mais conditionnel, à l'élection de Jean-Claude Juncker, assorti de l'exigence d'une inflexion notable de la politique européenne en faveur de l'investissement et de la croissance.

Il n'en demeure pas moins que, au lendemain des élections au Parlement et au travers de cet épisode, la question d'une réorientation souhaitable de la politique européenne est désormais ouvertement posée. Elle restera à l'ordre du jour au moins pour les six mois qui viennent à la faveur de la présidence de Matteo Renzi à la tête du Conseil européen et des discussions qui vont s'engager sur la définition du programme d'action des nouvelles instances européennes.

Les marges de manœuvre pour une politique de croissance menée à l'échelon de l'Eurogroupe ou de l'UE sont cependant étroites à la fois en raison de l'étroitesse du cadre budgétaire communautaire et du fait qu'elles demeurent, en l'état actuel des traités, circonscrites à des mesures d'ordre structurel. Imaginer, comme on s'entête à le faire dans une large partie des élites politiques et de l'intelligentsia économique parisiennes, qu'une politique de soutien à la croissance puisse raisonnablement passer par un relâchement du Pacte de stabilité relève de l'incongruité politique ou traduit pour le moins une méconnaissance persistante de la logique communautaire. Le Pacte de stabilité ne saurait être utilisé comme un instrument de régulation alors qu'il n'est qu'un cadre contractuel de règles communes dont le respect explicite constitue le garant d'une politique financière crédible de la zone Euro. Le Pacte est un contrat de copropriété monétaire, où chaque membre s'engage à tenir correctement ses finances, et non le compte courant d'une caisse commune sur laquelle chacun peut à sa guise tirer des chèques sur l'avenir.

Avec l'aggravation de la situation économique et financière du pays, l'idée finira peut-être par faire aussi son chemin en France, selon laquelle les marges de manœuvre pour retrouver la croissance ne se situent pas dans la dilution des règles communes de l'Union mais bel et bien dans la capacité de chacun des Etats membres à rétablir sur son territoire les bases d'une économie saine et d'une compétitivité retrouvée.

Pour peu que leurs dirigeants politiques et sociaux aient le courage de leur parler vrai, et devant le constat accablant d'une décennie de régression économique et sociale, les Français devraient finalement pouvoir se rallier à une idée simple : on ne construit pas de prospérité durable en continuant de creuser la dette et en espérant vivre au crochet de ses voisins. 